\title{
Patoloji Raporunda Yer Alan Tanılar Tekrarlanabilir mi?
}

\author{
Are the Pathologic Diagnosis Reproducible?
}

Alp USUBÜTÜN

Hacettepe Üniversitesi Tıp Fakültesi, Patoloji Anabilim Dalı, SIHHIYE, ANKARA

\section{ÖZET}

Patolojide tanı koyma sürecinde çok farklı etmenler rol alır. Patologların tüm sürecin farkında olmaları doğru tanı verme olasılığını arttıracaktır. Bu yazıda tıbbın belirsizliklerinden, tanı koyma sürecinin analitik değerlendirmesinden, kalite kontrolünün tanıdaki yerinden, "hatalı" ve "doğru" tanı kavramlarından, tanı uyumsuzluğu nedenlerinden, tanıların tekrarlanabilirliğini nasıl sağlayabileceğimizden söz edildi.

Anahtar Sözcükler: Sonuçların tekrarlanabilirliği, Patoloji, Kalite kontrol, Belirsizlik

\section{ABSTRACT}

A lot of factors affects the diagnostic process in pathology. Awareness of the pathologist about the diagnostic process may increase the accuracy of the diagnosis. In this review uncertainty of the medicine, analytic evaluation of the diagnostic process, place of the quality control in pathology, the concept of error and accuracy, factors effecting the diagnostic agreement and the reproducibility of the diagnosis were discussed.

Key Words: Reproducibility of results, Pathology, Quality control, Uncertainity

\section{PATOLOJI RAPORUNDA YER ALAN TANILAR TEKRARLANABILLIR Mİ?}

Son yllarda tüm tıp disiplinlerinde "tanısal uyum" değerlendirme çalışmalarında artış olduğu dikkat çekmektedir. Örneğin Pubmed'de "reproducibility of results" yazdığınızda karşınıza 284.897 makale çıkmaktadır. Patoloji dergilerini de gözden geçirirseniz çok sayıda "tanısal uyum" çalışması olduğunu görebilirsiniz. Bu çalışmaların bazı örneklerini bu makale içerisinde de görebilirsiniz. Aslında aynı kriter ve yöntemleri kullanmalarına karşın patologların farklı sonuçlara varabilecekleri ve bunun da ne kadar yaşamsal olduğu da uzun zamandır bilinmekteydi (1). Günlük pratikte karşılaşılan uyum sorunlarının yıllardır bilinmesine karşın, tedavi alternatiflerinin giderek çeşitlenmesi ve özellikle belli tanılar için hedefe yönelik tedavilerin ortaya çıması daha kesin sınırlar ile ayrılmış tanı verme gereksinimini arttırmıştır. Hedefe yönelik tedaviler pahalı da olduklarından, maliyet etkinlik açısından da kesin sonuçlara gereksinim göstermektedir. Böylece hastalara daha etkin, daha az zarar veren tedavileri uygulama olanakları ortaya çıkmıştır. Aynı şekilde, hastaya daha az zarar vermeyi amaçlayan daha konservatif tedavi yöntemlerinin kullanılmaya çalışılması, kanser öncülü lezyonların çok erken

(J Curr Pathol 2017, 1:8-11)

Geliş Tarihi : 14.08.2014 Kabul Tarihi : 15.08.2014 dönemlerde saptanabiliyor oluşu da kesin ve doğru tanı verme gerekliliği oluşturmaktadır. Bu nedenle de özellikle sorun yaşanan alanlarla ilgili olarak patologlar arası uyum çalışmaları yapılmakta daha yüksek tanı uyumuna nasıl ulaşılabileceği araştırılmaktadır.

\section{Tıpta Belirsizliklerin Varlığından Haberdar Olmak}

Yıllar önce çok tanınan bir tıp doktoruna, o yıllardaki mesleki yeteneklerine çok güvenilen iki patolog tarafından yanlış tanı konması çevremdeki birçok hekimi çok şaşırtmış bunun nasıl olabileceği konusundaki merakları bana "Hekim hata yapar mı?" yazısını yazmama neden olmuşlardı (2). O dönemde Renee Fox'un ortaya koyduğu tıbbın belirsizlikleri ile tanışmış ve tıbbın kesin olmayan birçok durum içerdiğini görmüştüm (3). Fox'a göre tıpda iki önemli belirsizlik kaynağı vardır, bunlardan birisi güncel bilimsel bilginin henüz açıklayamadığı alanlar ve diğeri hekimin bilgi birikimini aşan durumların varlığı. O zaman anlaşılmayan bir durum ile karşılaşıldığında ya bu durum değerlendiren kişi tarafından bilinmemektedir ya da henüz bilimsel olarak tanımlanmamıştır. Bu tesbitler, henüz her şey bilinmiyor ve bir hekim her şeyi bilemez sonucuna götürmektedir. Dolayısı ile, hekimlerin tıpta var olan belirsizliklerin farkına varmaları ve bu belirsizliklerle baş

\footnotetext{
İletişim: Alp USUBÜTÜN

Hacettepe Üniversitesi Tip Fakültesi,

Patoloji AD, SIHHIYE, 06100, ANKARA

E-posta: alpusubutun@yahoo.com Tel: +90 3123051563
} 
etmeyi öğrenmeleri, meslek hayatlarında başarılı olmalarının önemli bir basamağı olduğu görülmektedir (3). Buna karşın hekimlerin bu durumun farkına varmaması ve ortaya çıkan sorunların savunmacı bir tarz ile geçiştirilmesi başarısız bir meslek yaşantısına neden olmaktadır (3).

\section{Patolojide Kalite Kontrolü ve Hatanın Önlenmesindeki Rolü}

Doğru tanıya giden yolda belirsizlikler olduğu ve tanı koyacak hekimin belirsizlikler ile başedecek yöntemler geliştirerek hedefine ulaşması gerektiği ortadadır. Ancak doğru tanıya ulaşmak için bu farkındalık yeterli midir? Tıbbın kendi doğasından kaynaklanan belirsizliklerin yanı sıra birçok etmene bağlı olarak ortaya çıkabilecek hatalar da doğru tanının düşmanları olarak ortada durmaktadır. Gerçekten dokuların karışmasından, patologun yorgunluğuna kadar birçok etmen hatanın ortaya çıkmasına neden olabilmektedir. Bugün, hataları en alt seviyelere indirebilmek için rutin uygulamalar içinde genel kabul gören birçok standartlar geliştirilmiştir ve patoloji laboratuvarlarının kalitesini yükseltmeyi hedeflemektedir (4). Patolojide de kalite arttırıcı yöntemler giderek daha standart hale gelmekte olup akreditasyon programları halinde gelecekte patoloji laboratuvarlarının olmazsa olmazları arasına gireceklerdir. Kalite geliştirici yöntemler ile karışılklılar ve hatalar engellenebilir, daha standart tanılar elde edilebilir.

\section{Hatanın Kesin bir Tanımı Yapılabilir mi?}

Her ne kadar "doğru tanı" ve "hata" gibi terimler kullansak da aslında henüz bu kavramların sınırlarını kesin olarak çizebilmiş değiliz. Patolojide "doğru tanı" nedir? veya tersten sorarsak "yanlış tanı" nedir? Bu soruları genel olarak tanımlamak zor olmamakla beraber, kesin sinırları çizmek kolay değildir. Örneğin bazı lezyonlara kesin tanı vermek ancak eksperlerin sayesinde olmaktadır. O zaman eksper tanısı mıdır doğru olan? Eksper bir patologun benign olarak tanı koyduğu bir lezyon metastaz ile hastanın ölümüne neden olursa, hastanın izlemi mi midir bize kesin tanıyı koyduran. Hasta izlemi ile tüm sorulara yanıt bulabilir miyiz? Çok yavaş seyreden malign bir neoplazmın tanısını teyit etmek için kaç yıl izlemeliyiz? Ya da çok yavaş seyirli ve radikal cerrahisi yapılmış bir lezyonda izlem bize kesin benign / malign ayrimında ipucu verir mi? Gördüğünüz gibi hasta izlemi bile bize kesin sonuç vermeyebilir kaldı ki sonucu sinamak için tüm hastaları izlemek de hiç kolay bir yaklaşım değil. Sonuç olarak "hatalı veya doğru tanıyı" tam olarak tanımlamak güçtür.

Patologlar arası tanı uyumunu tartışmaya geçmeden bir noktayı daha anımsamakta yarar var. Tanı uyumunun sağlanmış olması doğru tanıya ulaşıldığı anlamına da gelmez. Üzerinde tamamen fikir birliğine ulaşılarak konulan tanıların yanlış olma olasılıkları da vardır. Yani herkes yanlış tanıda uzlaşabilir. Görüldüğü gibi patolojide tanı koymak, mayınlı bir tarlada dolaşmaktan farksızdır. Çok boyutlu böyle bir konuda öncelikle patologların tanıya nasıl ulaştıklarını irdeleyerek başlamak istiyorum.

\section{Patolog Bir Lezyona Nasıl Tanı Koyar}

Patoloji raporuna tanının yazılana kadar geçen süreçlere, tanının nasıl konulduğunu anlamak açısından bakmakta yarar vardır. Her patolog tanı koyma sürecini, genel olarak yaptıklarını düşünerek rahatlıkla özetleyebilir; Hasta hakkındaki klinik verilerin, makroskopik değerlendirme bulgularının, mikroskopik inceleme ve gerekli olursa diğer ek yöntemlerden gelen bilgilerin üst üste konması ile tanı koyduğunu rahatlikla söyleyebilir. Bu süreci analitik olarak değerlendiren Pena GP ve ark. tanı koyma sürecini bir problem çözme stratejisi olarak görüp, patologların 4 ayrı alanda değerlendirme yaparak sonuca ulaştıklarından söz etmektedir; bu alanlar

1. Bilişsel alan

2. Iletişim alanı

3. Normativ alan

4. Tıbbi yönetim alanlarıdır (5).

Çok detayına girmeden kısaca bunlardan söz edecek olursak; bilişsel alanda patolog algı ve bellek gibi bilişsel süreçleri kullanıyor ve olgu hakkındaki bilgileri (makroskopik, mikroskopik vb) toplayıp bir hipoteze ulaşıyor ve bunu sinıyor. Tanıya ulaşmak için iletişim ve dil de önemli bir rol oynuyor, gerektiğinde klinisyen veya hasta ile konuşup bilgi almak ve tanıyı yazılı hale getirmekte bu alan içerisinde tanımlanıyor. Normativ alan, tüm kuralları oluşturuyor, teknik yöntemlerin prosedürlerinden (immünohistokimya yapma prosedürü vb), bir tümörün sinıflandırılması ya da derecelendirilmesi kuralları bu alanın içerisinde tanımlanıyor. Dördüncü olarak da tıbbi yönetim alanında, tüm tanılar rapor haline gelmeden patolog tarafından tıbbi olarak hangi sonuca neden olacağı değerlendiriliyor ve patolog tıbbi işlemlerin sorumluluğunu alarak patoloji raporunu imzalıyor. Burada da görüldüğü gibi tanı birçok farklı alanda değerlendiriliyor ve nihai sonuca ulaşıllyor. Bu çok basamaklı süreçler, patoloji raporunda kişiler arasında ciddi değişkenlikler oluşmasına neden olabilmektedir.

\section{Tanısal Uyumsuzluğun Kökenleri Nerededir?}

Cerrahi patolojide tanısal farklılıklar, sınıflananlar arasındaki değişkenliğe, sinıflayanlar arasındaki değişkenliğe ve sınıflama sisteminin sorunları ve sinıflayan ile sinıflanan arasındaki etkileşim yöntemlerine bağlıdır (6). Neyi sınıfladığınız önemli, örneğin genel olarak endometrial kanserleri sinıflandırırsanız iyi bir uyum elde ederken, yüksek dereceli endometrial kanserleri sinıflamak isterseniz gözlemciler arası uyum düşmektedir (7). Trofoblastik hastalıklar gibi bazı lezyonları gözlemciler arası uyumu sağlayarak sınıflamak ise oldukça güç görünmektedir (8). Burada bu kadar farklılığa neden olan, lezyonların tanımlarının ne derece yapıldığıdır. Sınıflandırma yapılırken birbiri ile karışan lezyonlar morfolojik olarak ne kadar iyi tanımlanmış ve biribirinden ayıran bulgular ne kadar keskin sınırlar ile belirtilmişse uyum o kadar yüksek 
olmakta, sınırların bulanıklaştığı lezyonlarda uyum o oranda azalmaktadır. Mol tanısının ve sınıflandırmasının kişiler arası uyumu düşüktür çünkü hidropik villuslar ile parsiyel mol veya erken komplet mol arasındaki morfolojik sınırlar çok keskin değildir. Bu da birbirleri ile kesişen tanı kategorileri anlamina gelmektedir. Bu nedenle sadece morfolojik bulgular ile sınıflama yapıldığında tanı uyumları çok düşüktür. Buna karşın mol tanısı ve sınıflandırmasında morfolojiye ek olarak immünohistokimya veya moleküler yöntemler kullanıldığında gözlemciler arası uyumda belirgin bir artış gözlenmektedir (8). Bu da gözlemcilere, tanı sınırlarını belirleyen ek tanısal araçlar vermenin uyumu arttırdığını göstermektedir.

\section{Sinıflama Sisteminin Tanısal Uyumdaki Rolü}

Endometrial hiperplazilerde gözlemciler arası uyum oldukça düşüktür (9). DSÖ endometrial hiperplazi sınıflamasını yapan grubun içinde bulunan Kurman'n kendi ekibinin yaptığ 1 uyum çalışmasında bile en can alıcı kategori olan atipik hiperplazi (kanser öncülü olduğundan hastada tedavi yöntemi değiștirir o nedenle klinik öneme sahiptir) gözlemcilerden en düşük uyumu almıştır (10). Endometrial hiperplazileri moleküler patogenezini göz önüne alarak morfolojik kriterler geliştirilen "endometrial intraepitelyal neoplazi" (EIN) sınıflamasında ise uyum daha yüksektir (11). Bunun nedeni tanı verilerken bazı özgün kriterlerin kullanılmıs olmasıdır (12). Bir önceki sınıflandırma atipi için bez sayısının artışından söz ederken EIN sınıflandırması \%50'den fazla artış kriteri, yine DSÖ sınıflandırmasında atipik hücrenin morfolojik tarifi yapilırken EIN sinfflamasında normal bez ile karşılaştırma kriteri getirilmiştir, bu kriterler yoruma yer birakmayacak şekilde morfolojik sınırları daha kesin olarak tanımladığından gözlemciler arası uyumu yükseltmiştir (11).

HPV bağlı gelişen lezyonlarda da düşük dereceli olanlar (LSIL) genellikle tedavi gerektirmezken yüksek dereceli olanlar (HSIL) cerrahi tedaviye gereksinim gösterir. Buna karşın birçok çalışma birbirine benzer sonuçlar üretirken, en geniş serilerden birisi servikal lezyonlarda hem sitolojik hem de biyopsi tanı uyumlarının düşük olduğunu ve biyopsi materyallerinde en büyük sorunun düşük dereceli lezyonları ayırt etmekte yaşandığını göstermektedir (13). Bazı yazarların kategorik olarak varlığına şüphe ile baktıkları CIN2 tanısı uyumun en düşük olduğu gruptur (13). Yüksek riskli HPV'ler için çok spesifik olması nedeniyle immünohistokimyasal belirleyici olan pl6'nın tanısal uyumu arttıracağını düşünülmekle beraber son çalışmalarda uyumu arttırmak üzerine belirgin bir etkisi olmadığı görülmektedir (14). Henüz yayınlanmamış bir çalışmamızda da kendi gözlemimiz, her vakada kullanıldığında p16 nın gözlemciler arası uyuma bir katkı yapmadığıdır. Çünkü p16 yüksek riskli HPV varlı̆̆ını gösterir ancak düşük dereceli lezyonlarda yüksek riskli HPV bulunabildiğinden pl6 pozitifliği HSIL kanıtı değildir. Konuyu bu kadar ayrıntılı anlatmamın nedeni çok özgün bir belirleyici bulunmasına karşın, HPV bağlı gelişen lezyonlarda LSIL ve HSIL patogenezi tam olarak aydınlatılmadığından, buna karşılık gelecek morfolojik bulgular ve diğer yardımcı yöntemlerde tanımlanamamıştır. Bu nedenle tanıda kişisel yorumlar ağırlık kazanmakta ve bazı hastalar fazla ve bazı hastalar yetersiz tedavi edilebilmektedir. Sonuç olarak bir tanı kategorisinin patogenezi ne kadar iyi anlaşılmış ise morfolojik bulgular da o kadar iyi tanımlanmakta ve gözlemciler arası uyum o oranda yüksek olmaktadır.

\section{Patologun Tanısal Uyumdaki Rolü}

Her yiğidin bir yoğurt yiyişi vardır deyişine uyumlu olarak gözlemcilerin de kendilerine özgü davranış patternleri vardır. Bireysel tanısal yaklaşımlar büyük değişimler gösterebilmektedir, hatta ülkelerin yasal alt yapılarına göre patologların tanısal yaklaşımlarının, morfolojiden bağımsız olarak değişimler gösterebileceği düşünülmektedir (1). Bunun en iyi örneklerinden birisi Japonya'da yaşayan patologlar benzer lezyonlara ABD ve Avrupa'da yaşayan patologlara göre daha yüksek oranda mide ve kolon kanseri tanısı vermektedirler $(15,16)$. Birçok meslektaşımla paylaştığım kendi kişisel gözlemim, tedavi konusunda daha radikal yöntemleri tercih eden cerrahlarla çalışan patologların tanı konusunda daha konservatif davrandıkları yönündedir. Türkiye'de yapılan ve endometrial lezyonları değerlendiren bir uyum çalışmasında, patologlar 3 ayrı tanı kategorisinde kümelendiler; daha benign tanı vermeye eğilimli olanlar, daha çok preneoplastik lezyon tanısı verme eğiliminde olanlar ve orta yolda yer alanlar (ne o ne bu, hem o hem bu) olmak üzere 3 gruba ayrilmışlardır (11). Aslında deneyimli patologun günlük patoloji pratiğinde de, tanıdıkları içerisinden hangi patologun hangi lezyona ne diyeceğini kestirebileceğini gayet iyi biliyoruz.

Patologların genel yaklaşım farklılıkları dışında da her lezyon için bir kendilerine özgü, var olan kriterleri temel alan yorum kriterleri olduğunu da söylememiz lazım. Yani kısaca her patolog var olan kriterleri kendi değerlendirme sürecinden geçirmekte ve yorumlamaktadır. Bunu destekleyen en önemli bulgu, eğer gözlemciler tanı vermeden önce biraraya gelip tanı kriterlerini kendi aralarında tartışılarsa tanı uyumu artmaktadır (17). Literatürde çok kapsamlı intraobserver çalışmalar yoktur. Ancak kişisel olarak benzer lezyonlara diğer patologlar ile bakarken genellikle her patologun kendine özgü bazı kriterleri olduğunu gözlemekteyim. Bu da var olan kriterlerin kişisel olarak yorumlandığı şeklinde değerlendirilebilir. Özet olarak her patologun da, sinıflayacağ 1 lezyonlar için kendisi için tasarlanmış bir kriterler yorumu olduğunu söylemek yanlış olmaz.

\section{Ne Yapılabilir?}

Tüm bu etmenler nedeniyle tanısal uyum sorunu daha uzun zaman patologların gündemini işgal edecekmiş izlenimi veriyor. Tanı kategorileri keskin sınırlar ile morfolojik olarak tanımlanana veya moleküler genetik veya immünohistokimyasal ek yöntemler ile yeni ayrım sağlanana kadar bu durum sürecekmiş gibi görünüyor. Tanı uyumu ile ilgili bu çalışmalar sürerken, daha karşılaştırılabilir sonuçlar alabilmek için çalışmalarda standart rehberlerin kullanılması ve kuralların tanımlanmasının gereği giderek daha çok anlaşılmakta ve çeşitli 
gruplar tarafından uyum çalıșmalarında kullanılmak üzere önerilen standart rehberler bulunmaktadır (18).

Unutmamak gerekir ki bu uyumsuzluklar zaman zaman tedavide radikal değişikliklere neden olurlar. Özellikle erken öncül lezyonların tarama programları ile saptandığı ülkelerde, o tümörler için yalancı epidemilerinin oluştuğu, yani hastalara "overdiagnosis" yapıldığı bilinmektedir $(19,20)$. Bunların sonucu birçok hasta hiç gerekmediği halde ciddi radikal tedaviler almaktadır. Sanırım bu sürece patologların da katkısının olmadığını söylemek güçtür. Genellikle patologların ayırıcı tanıda sıkıntı yaşadıklarında, tanı spektrumu içerisinde yer alan daha yüksek dereceli lezyon lehine karar verdikleri hepimizin bildiği bir gerçektir (21). Bu da daha fazla tedavi anlamını taşımaktadır.

Peki tanı uyumu düşük olan lezyonlarda bugün pratik olarak ne yapılabilir? Kanımca bu sorunun pratik güncel çözümü patologların tedavide karar verici rolünün arttırılmasıdır. Sadece patoloji raporunda yazan tanı üzerinden klinisyenin karar vermesi yerine sorunlu lezyonlarda çözümün patolog ile klinisyenin karşılıklı tartışmaları ile tedavinin planlanmasıdır. Aynı patoloji raporları farklı klinisyenlere gösterildiği ve yorumlarının sorulduğu çalışmalarda, farklı klinisyenlerin aynı rapordan farklı sonuçlar çıkardığını biliyoruz (22). Klinisyenler ile patologların algı dünyalarının farklı olduğunu ve iyi bir iletişim olmaz ise bunun sorunlara yol açabileceğini görebiliyoruz (23). Bu nedenle konunun uzmanı patolog ile konunun uzmanı klinisyen arasındaki sözel diyalog, bu sorunların en iyi çözümü gibi görünüyor. Önemli olan tüm bu sorunların farkında olarak hastaya azami yarar veya en az zarar getirecek tedavi seçeneğinin bulunmasıdır. Durumun farkında olmamak ise baştan kaybetmek demektir.

\section{KAYNAKLAR}

1. Foucar E. Error Identification: A Surgical Pathology Dilemma. Am J Surg Pathol. 1998;21(1):1-5.

2. Usubutun A. Hekim Hata Yapar mı? Sürekli Tıp Eğitimi Derg 1995;4(9):301-3.

3. Anderson RE, Fox RC HR. Medical uncertainty and the autopsy: occult benefits for students. Hum Pathol. 1990;21(2):128-35.

4. Nakhleh R, Coffin C, Cooper K. Recommendations for quality assurance and improvement in surgical and autopsy pathology. Am J Clin Pathol. 2006;126(3):337-40.

5. Pena GP, Andrade-Filho JDS. How does a pathologist make a diagnosis? Arch Pathol Lab Med [Internet]. 2009 ;133(1):12432.

6. Foucar E. "Individuality' in the specialty of surgical pathology: self-expression or just another source of diagnostic error? Am J Surg Pathol. 2010;24(11):1573-6.

7. Gilks CB, Oliva E, Soslow R a. Poor interobserver reproducibility in the diagnosis of high-grade endometrial carcinoma. Am J Surg Pathol [Internet]. 2013 Jun;37(6):874-81.
8. Vang R, Gupta M, Wu L, Yemelyanova A V, Kurman RJ, Murphy KM, et al. Diagnostic Reproducibility of Hydatidiform Moles: Ancillary Techniques ( p57 Immunohistochemistry and. Am J Surg Pathol. 2012;36(3):443-53.

9. Bergeron C1, Nogales FF, Masseroli M, Abeler V, Duvillard P, Müller-Holzner E, Pickartz H WM. A Multicentric European Study Testing the Reproducibility of the WHO Classification of Endometrial Hyperplasia With a Proposal of a Simplified Working Classification for Biopsy and Curettage Specimens. Am J Surg Pathol. 1999;23(9):1102-8.

10. Kendall BS1, Ronnett BM, Isacson C, Cho KR, Hedrick L, DienerWest M KR. Reproducibility of the Diagnosis of Endometrial Hyperplasia, Atypical Hyperplasia, and Well-Differentiated Carcinoma. Am J Surg Pathol. 1998;22(8):1012-9.

11. Usubutun A, Mutter GL, Saglam A, Dolgun A, Ozkan EA, Ince $\mathrm{T}$, et al. Reproducibility of endometrial intraepithelial neoplasia diagnosis is good, but influenced by the diagnostic style of pathologists. Mod Pathol. $2012 ; 25(6): 877-84$.

12. Online "Mini Lectures" [Internet]. Available from: http:// endometrium.org/Docs/Videos.htm

13. Stoler MH, Schiffman M. Interobserver reproducibility of cervical cytologic and histologic interpretations: realistic estimates from the ASCUS-LSIL Triage Study. JAMA. 2001 21;285(11):1500-5.

14. Pacchiarotti A1, Galeotti S, Bellardini P, Chini F, Collina G, Dalla Palma P, Ghiringhello B, Maccallini V, Musolino F, Negri G, Pisa R, Sabatucci I GRP. Impact of p16(INK4a) immunohistochemistry staining on interobserver agreement on the diagnosis of cervical intraepithelial neoplasia. Am J Clin Pathol. 2014;141(3):367-73.

15. Schlemper RJ1, Itabashi M, Kato Y, Lewin KJ, Riddell RH, Shimoda T, Sipponen P, Stolte M WH. Differences in the diagnostic criteria used by Japanese and Western pathologists to diagnose colorectal carcinoma. Cancer. 1998;82(1):60-9.

16. Schlemper RJ, Itabashi M, Kato Y, Lewin KJ, Riddell RH, Shimoda T, Sipponen P, Stolte M, Watanabe H, Takahashi H FR. Differences in diagnostic criteria for gastric carcinoma between Japanese and western pathologists. Lancet. 1997;349(9067):1725-9.

17. De Vet HCW, Koudstaal J, Kwee WS, Willebrand DAJ. Efforts to improve agreement in histopathological grading. J Clin Epidemiol. 1995;48(7):869-73.

18. Kottner J, Audigé L, Brorson S, Donner A, Gajewski BJ, Hróbjartsson A, et al. Guidelines for Reporting Reliability and Agreement Studies (GRRAS) were proposed. J Clin Epidemiol [Internet]. 2011 Jan;64(1):96-106.

19. Adami H-O. The prostate cancer pseudo-epidemic. Acta Oncol [Internet]. $2010 ; 49(3): 298-304$.

20. Brawley OW. Cancer screening. Semin Oncol. 2004;31((2 Suppl 4)):47-53.

21. Usubütün A, Ertoy D, Ozkaya O, Altinok G KT. Search for problem areas in endometrial biopsies to achieve quality assurance. Pathol Res Prac. 2000;196(9):625-6.

22. Powsner SM, Homer RJ. Clinicians Are From Mars and Pathologists Are From Venus Clinician Interpretation of Pathology Reports. Arch Pathol Lab Med. 2000;124:1040-6.

23. Heffner DK. Pathologists are from Mercury, clinicians are from Uranus: the perverted prospects for perceptual pathology. Ann Diagn Pathol. 2008;12(4):304-9. 